\title{
Growth Characteristics and Ergosterol Content of Grifola frondosa in Various Solid-state Substrates
}

\author{
A. Gregori, ${ }^{a}$ M. Švagelj, ${ }^{b}$ D. Voglar, ${ }^{b}$ and M. Berovic ${ }^{b, *}$ \\ anstitute for Natural Science, Ul. Bratov Ucakar 108, SI-1000 Ljubljana \\ ${ }^{b}$ Department of Chemical, Biochemical and Environmental Engineering, \\ Faculty of Chemistry \& Chem. Technology, University of Ljubljana, \\ Vecna pot 113, 1000 Ljubljana, Slovenia
}

doi: 10.15255/CABEQ.2015.2306

Original scientific paper

Received: September 22, 2015

Accepted: June 22, 2016

Growth characteristics of medicinal mushroom Grifola frondosa mycelia were studied in solid-state cultivation on various solid-state substrates in different setups. The mycelial growth rate was determined in racing tubes by the measurement of ergosterol content. The fastest growth rate of $3.76 \mathrm{~mm} \mathrm{~d}^{-1}$ and the highest biomass amount of $54 \mathrm{mg} \mathrm{g}^{-1}$ were achieved. The results were scaled-up in a horizontal stirred bioreactor, where higher amounts of biomass ( $53.2 \mathrm{mg} \mathrm{g}^{-1}$ in 42 days) were achieved. These results represent an available platform for large-scale production of medicinal fungi biomass in bioreactors.

Key words:

Grifola frondosa, biomass, racing tubes, ergosterol, horizontal stirred bioreactor

\section{Introduction}

Grifola frondosa (Dicks: Fr) S.F. Gray is a white rot basidiomycete, belonging to Basidiomycotina, Homobasidiomycetes, Aphyllophoromycetideae, Polyporales, Family Meripilaceae ${ }^{1}$. The mushroom (Figure 1) is known under several English names (Dancing mushroom, Cloud mushroom, Hen-of-the-woods, the Dancing Butterfly mushroom, Sheep's head), in Japan as Maitake, and in China as Hui Shu Hua. Fresh and dried G. frondosa fruit bodies, which are commonly available in food markets of Asia, especially of Japan, China and Korea, have also become available in other countries, such as the USA, Canada, and EU. Numerous nutraceutical preparations based on G. frondosa powdered fruit bodies, dried extracts or purified polysaccharides are emerging in different forms - as capsules, tablets, as well as additives to food formulations.

Grifola frondosa mycelium and its polysaccharides can be produced in liquid media ${ }^{2}$ as well as solid-state cultivation on sunflower seed huls ${ }^{3}$ and different grain types ${ }^{3,4}$, while fruiting bodies are usually cultivated on broadleaf sawdust-based substrates with addition of different supplements, such as wheat bran, crushed cord seeds ${ }^{5}$, olive oil press cakes $^{6}$ and others. Commercially, polypropylene bags or bottles are used as substrate containers from which fruiting bodies emerge.

*Address all correspondence to Marin Berovic: Tel: + 38614798573 ; marin.berovic@fkkt.uni-lj.si
Fruiting bodies are large, soft-fleshed, edible, and consist of approximately 86-91\% moisture and 9-14\% dry matter, of which carbohydrates represent $59-60 \%$, crude protein $21-22 \%$, crude fiber $10 \%$, crude fat $3-4 \%$, and ash $5-7 \%{ }^{1,7}$. Fruiting bodies also contain ergo sterol, assorted vitamins and minerals ${ }^{8}$.

Grifola frondosa fruit bodies often occur as a heavy mass at the base of stumps and on the roots of dead or dying deciduous hardwoods, such as Quercus, Ulmus, Acer, Nyssa, Larix and Fagus; sporadically also on Castanea, Prunus, Pseudotsu$g a$ and Pinus. The optimal growing conditions exist within a limited range of temperature, moisture, humidity, and other environmental factors. Parts of northeastern Japan are especially hospitable for this mushroom, although it can also be found in the northern temperate forests of Asia, Europe, and eastern North America9.

Beside the references cited above, other broadleaf sawdust types could have a potential use for $G$. frondosa biomass and fruiting bodies cultivation. In this article, G. frondosa mycelium growth traits on selected substrates composed of beech, Norwegian spruce, European larch and common grape vine sawdust were conducted, and fungal biomass were determined. This work represents the investigation of presently unexploited raw materials for $G$. frondosa biomass and fruiting bodies production. Substrate compositions with the best characteristics for $G$. frondosa growth were evaluated, selected, and applied in a pilot solid-state horizontal stirred bioreactor. 


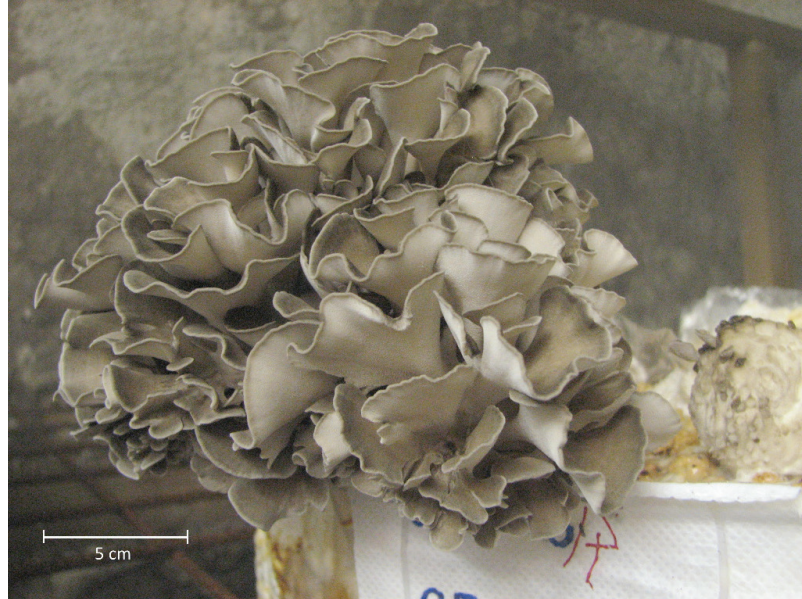

Fig. 1 - Fruiting body of G. frondosa in artificial cultivation on beech sawdust supplemented with wheat bran

\section{Materials and methods}

\section{Microorganism and seed culture preparation}

Grifola frondosa (Dicks: Fr) S.F. Gray strain GF3, original strain from Slovenian forests used in this study, was isolated and is deposited at the Fungal bank of the Biotechnical Faculty, Department of Wood Science and Technology, University of Ljubljana, Slovenia. The culture was maintained at 28 ${ }^{\circ} \mathrm{C}$ on potato dextrose agar - PDA (Difco, USA), and transferred every two weeks onto freshly prepared media. Liquid inoculum for PDA plate inoculation was prepared by mixing a two-week-old PDA plate overgrown with $G$. frondosa mycelium in 200 $\mathrm{mL}$ sterilized deionized water in a S700 blender (Waring products, Calhoun, GA, USA), three times, for 20 seconds.

The seed culture for the pilot solid-state reactor was prepared by transferring $50 \mathrm{~mL}$ of the liquid inoculum to $450 \mathrm{~mL}$ sterilized liquid growth medium composed of glucose $\left(30 \mathrm{~g} \mathrm{~L}^{-1}\right)$, yeast extract $\left(6 \mathrm{~g} \mathrm{~L}^{-1}\right)$, peptone $\left(2 \mathrm{~g} \mathrm{~L}^{-1}\right), \mathrm{MgSO}_{4} \cdot 7 \mathrm{H}_{2} \mathrm{O}\left(0.5 \mathrm{~g} \mathrm{~L}^{-1}\right)$, $\mathrm{K}_{2} \mathrm{HPO}_{4} \cdot 3 \mathrm{H}_{2} \mathrm{O}\left(0.66 \mathrm{~g} \mathrm{~L}^{-1}\right), \mathrm{MnSO}_{4} \cdot 1 \mathrm{H}_{2} \mathrm{O}\left(0.14 \mathrm{~g} \mathrm{~L}^{-1}\right)$, $\mathrm{pH}=5.5$ in a $1000-\mathrm{mL}$ Erlenmeyer flask. The seed culture was incubated for two weeks as a shaken culture at $28^{\circ} \mathrm{C}$ and $150 \mathrm{rpm}$.

\section{Mycelium growth in vitro}

Twenty-one petri dishes $(H=13 \mathrm{~mm}, r=43$ $\mathrm{mm}$ ) containing $35 \mathrm{~mL}$ of sterilized PDA were inoculated in the center of the PDA plate with $10 \mu \mathrm{L}$ of liquid inoculum. Incubation was performed at 28 ${ }^{\circ} \mathrm{C}$. Mycelium growth was followed with digital images analysis using the Motic Images Plus software (Motic China Group LTD) for 21 days, and expressed as radius of the circular growth zone. Once the mycelium overgrew the petri plate, it was carefully collected from the media surface, dried, weighed, and analysed for ergo sterol content.

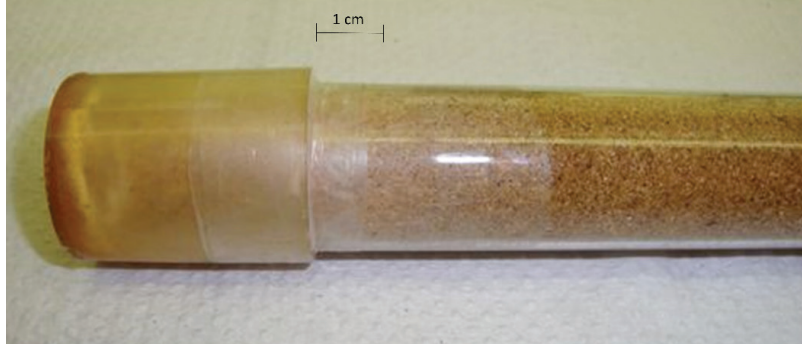

Fig. 2 - Racing tubes showing solid-state cultivation on beech sawdust substrate. Mycelial growth is visible with the naked eye.

\section{Substrates for solid-state cultivation}

Substrates were prepared from $76 \%$ dry weight beech (Fagus sylvatica), Norwegian spruce (Picea abies), European larch (Larix deciduas) or common grapevine (Vitis vinifera) sawdust (particle sizes from $0.125 \mathrm{~mm}-0.5 \mathrm{~mm}$ ) with the addition of wheat bran (20\% dry weight), $\mathrm{CaCO}_{3}$ (2\% dry weight), and olive oil (2\% dry weight). Substrates water content was adjusted to $65 \%$.

\section{Mycelium growth in racing tubes}

Growth rate measurements, biomass production, and ergosterol content were studied in solid-state bioprocessing conditions using "racing tubes". The method for growth rate measurements in the samples was developed. Glass tubes $175 \times 25$ $\mathrm{mm}$, (Figure 2) were filled with $28 \mathrm{~g}$ of substrate (substrate density of $0.35 \mathrm{~g} \mathrm{~mL}^{-1}$ ), closed on both sides with a plastic cap, and sterilized for $45 \mathrm{~min}$ utes at $T=121{ }^{\circ} \mathrm{C} ; p=1.2 \cdot 10^{5} \mathrm{~Pa}$. After cooling, the substrates were inoculated on one side of the tube with a 16-mm disc from a two-week-old PDA culture, and wrapped in parafilm to prevent moisture loss. The inoculated substrate in the racing tubes was incubated at $28^{\circ} \mathrm{C}$ and mycelium growth was monitored periodically using a stereo microscope joined with a precision measuring tool. The length of the linear growth zone of mycelia in the racing tubes in different time-points represents the growth rate. All experiments were performed in at least triplicate.

\section{Mycelium growth in glass jar bioreactors}

Cylindrical glass jars of $700 \mathrm{~mL}$ volume were used as containers for fungal biomass cultivation. They were filled with $400 \mathrm{~mL}$ of substrate, and closed with a cotton filter lid for air exchange. The substrates were sterilized for $45 \mathrm{~min}$ at $T=121^{\circ} \mathrm{C}$; $p=1.2 \cdot 10^{5} \mathrm{~Pa}$, inoculated with $5 \mathrm{~mL}$ of liquid inoculum, thoroughly mixed and incubated at $28^{\circ} \mathrm{C}$ for 7 days. Samples were obtained every three days, and the ergosterol and moisture content determined. All experiments were performed in triplicate. 
Electron micrographs of $G$. frondosa mycelium on solid-state substrates were performed with a Field-emission Scanning Electron Microscope at an accelerating voltage of $1 \mathrm{kV}$ (Carl Zeiss Supra 35 $\mathrm{VP})$.

\section{Mycelium growth in horizontal stirred tank bioreactor}

The best substrate formula (and perhaps time of solid-state cultivation) from the previous step the glass jar bioreactors, were scaled up in an ad hoc 15-L horizontal stirred tank bioreactor. Details of the construction of this device are shown in Figure 3. The reactor was filled to two-thirds depth with substrate ( $3500 \mathrm{~g}$ of beech sawdust substrate), sterilised in situ for 120 minutes $\left(T=121{ }^{\circ} \mathrm{C} ; p=\right.$ $1.2 \cdot 10^{5} \mathrm{~Pa}$ ), and cooled to the inoculation temperature. Substrate was inoculated with $500 \mathrm{~mL}$ of seed culture, and incubated at $28{ }^{\circ} \mathrm{C}$. Periodical mixing $(80 \mathrm{rpm})$ by horizontal blades attached to a central shaft, for two minutes/day, and aeration over a hollow shaft of the impeller ( $5 \mathrm{~L} \mathrm{~h}^{-1}$ air flow) were applied. The same principles of process optimization as inoculation, sterilization, mixing, aeration, temperature, and humidity were applied as in our previous works ${ }^{6,10}$.

\section{Ergosterol and biomass determination}

Ergosterol was determined applying a modified method described by Gregori (2014) ${ }^{11}$. In brief, 10 $\mathrm{mg}$ of dry fungal biomass obtained from three petri dish PDA plates were extracted for 90 minutes with $1 \mathrm{~mL}$ of a solution of $10 \%(\mathrm{w} / \mathrm{v})$ polyvinylpyrrolidone (Sigma, Germany) in $96 \%$ ethanol, at $4{ }^{\circ} \mathrm{C}$ on a rotary shaker at $200 \mathrm{rpm}$. The resulting extract was centrifuged (10000 rpm, $15 \mathrm{~min}, T=4^{\circ} \mathrm{C}$ ), and filtered through a $0.45-\mu \mathrm{m}$ pore size filter. The fil- trate $(100 \mu \mathrm{L})$ was injected into a HPLC system (Varian, USA) with 1:1 (v/v) methanol:acetonitrile (Sigma, Germany) mobile phase at $1 \mathrm{~mL} \mathrm{~min}{ }^{-1}$ flow rate on a Synergi MAX-RP C12 column (Phenomenex, USA). Ergosterol was identified using standard retention time and specific peak between 260 and $300 \mathrm{~nm}$ obtained by calibration curve preparation using purified ergosterol standard (Sigma, Germany). For ergosterol determination in solid-state cultivation substrates, a 2-g sample was extracted with $20 \mathrm{~mL}$ of the same extraction mixture and subjected to the same procedure ${ }^{12}$.

\section{Moisture content determination}

The moisture content of substrate samples (grams) was determined with a HR83 Moisture Analyzer (Mettler-Toledo, Switzerland).

\section{Statistics}

All of the cultivation experiments were performed at least in three runs. The results were analyzed for statistical significance by one-way analysis of variance (ANOVA) test using the Statistical Package of the Social Science (SPSS) version 11.0 (SPSS Inc., Chicago, IL, USA). Statistical significance of the test effects was evaluated at $p<0.05$. Data were expressed as mean $\pm \mathrm{SD}$.

\section{Results and discussion}

\section{Mycelium growth in vitro and ergosterol content determination}

Ergosterol is a specific component of fungal cell membranes ${ }^{12}$. With ergosterol being in correlation to fungal biomass quantity, its determination

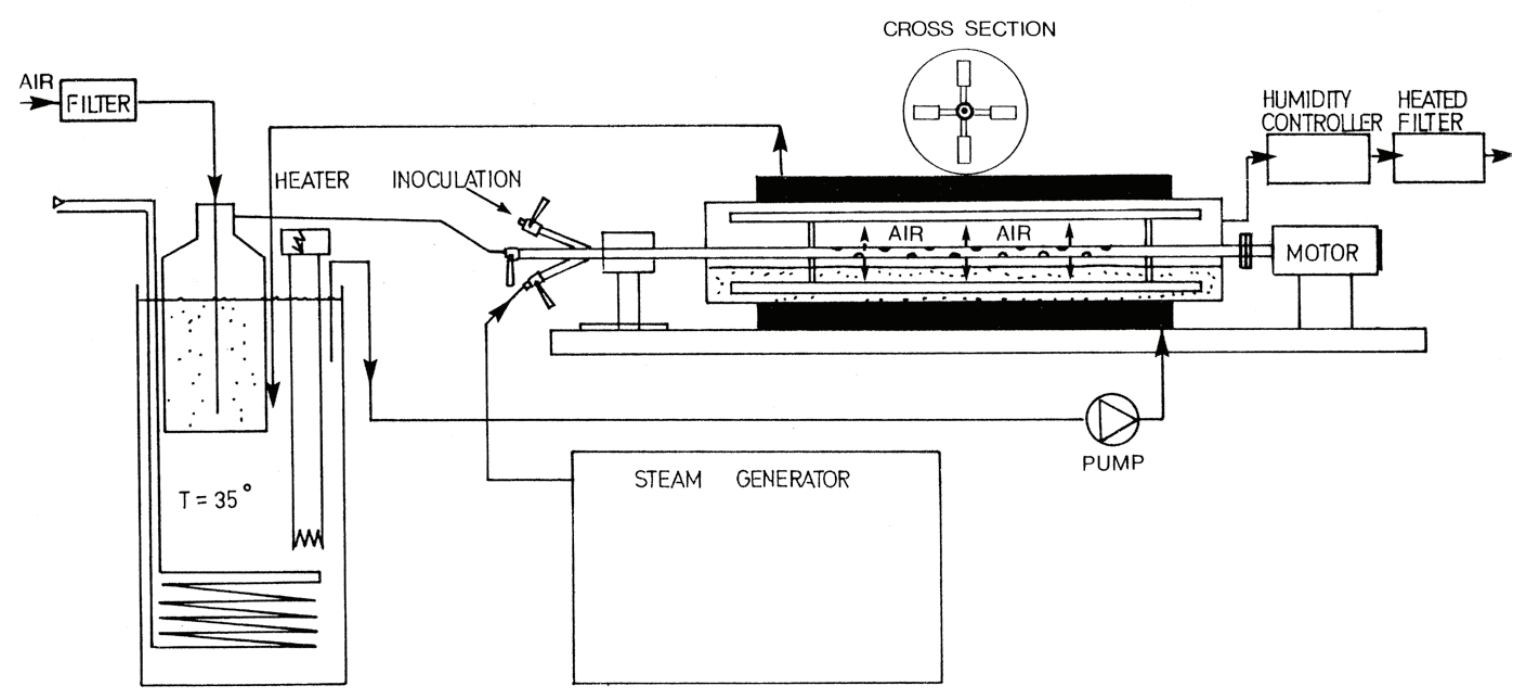

Fig. 3 - Scheme of horizontal stirred tank bioreactor - according to Berovic and Ostroveršnik (1997) 
can serve as an indicator for fungal growth rate. Figure 4 shows the mycelium growth until day 21 when it reached the borders of the petri plate in all experimental units.

Regarding the ergosterol content in dry biomass, it was found that it was constant throughout

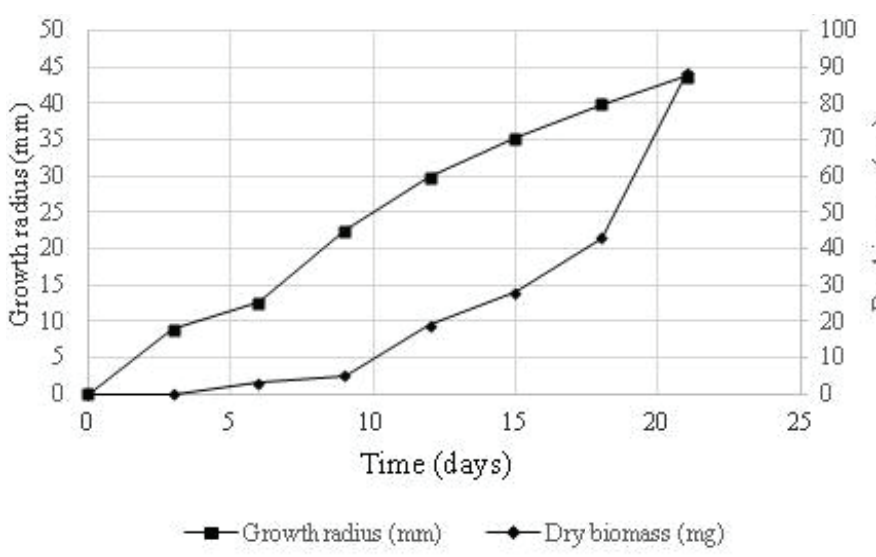

Fig. 4 - Mycelium growth in vitro. The growth radius and total dry biomass of $G$. frondosa mycelium on PDA medium are presented.

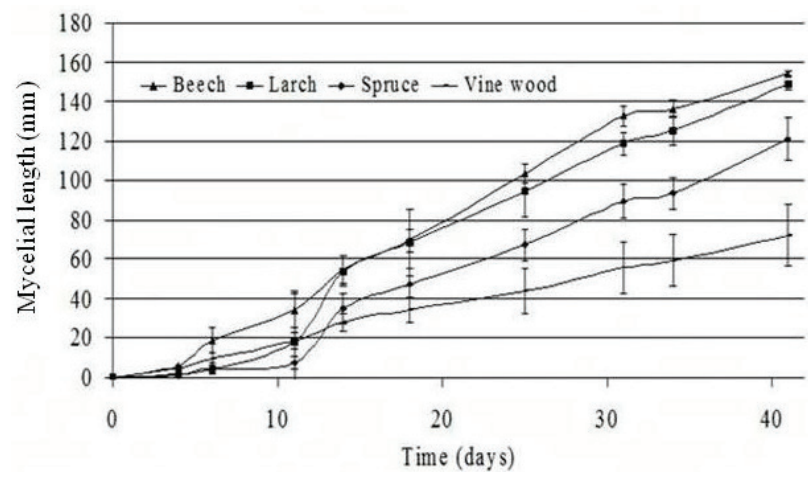

Fig. 5 - G. frondosa mycelium growth in racing tubes. The

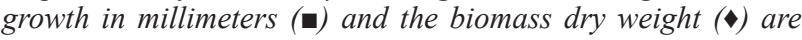
presented for different substrates formulations. the 21 days of the vegetative mycelium growth. The average content of ergosterol in the dried mycelium from the surface of PDA was $5.80 \mathrm{mg} \mathrm{g}^{-1} \pm 0.04$ $\mathrm{mg} \mathrm{g}^{-1}$. This value was used as reference to calculate the biomass content in the solid-state fermented substrates.

\section{Mycelium growth in racing tubes}

The growth rate of $G$. frondosa on different solid-state bioprocessed fermented substrates using the racing tubes test is shown in Figure 5. The highest growth rate occurred on beech sawdust-based substrate $\left(3.76 \mathrm{~mm} \mathrm{~d}^{-1}\right)$, followed by larch- (3.61 $\left.\mathrm{mm} \mathrm{d}^{-1}\right)$, spruce- $\left(2.95 \mathrm{~mm} \mathrm{~d}^{-1}\right)$, and common vine $\left(1.76 \mathrm{~mm} \mathrm{~d}^{-1}\right)$ based substrates. Larch- and sprucebased substrates presented a long lag phase that lasted about 12 days, while beech and common vine substrate had no noticeable lag phase.

\section{Mycelium growth in glass jars}

The mycelium growth rate of $G$. frondosa in solid-state bioprocessed substrates in glass jar bioreactors is shown in Figure 6. The highest dry biomass yield of $54 \mathrm{mg} \mathrm{g}^{-1}$ solid-state bioprocessed substrate was obtained at day 47 on the beech sawdust-based substrate. Next, were vine (49 $\left.\mathrm{mg} \mathrm{g}^{-1}\right)$, spruce $\left(40 \mathrm{mg} \mathrm{g}^{-1}\right)$ and larch sawdust $\left(30 \mathrm{mg} \mathrm{g}^{-1}\right)$ based substrate. Comparing the results from the race tubes and glass jar bioreactors, it was concluded that substrates composed of beech sawdust were more favorable for mycelial growth compared to other substrates. This is well in accordance with the fact that $G$. frondosa in natural habitats occurs mostly on beech wood ${ }^{8}$. The results for growth rates on substrates composed of spruce sawdust are comparable in terms of relative growth rate and biomass accumulation. The growth rate on spruce sawdust substrate was $78 \%$ higher, while in this case the accumulated biomass was only $74 \%$ of that ob-

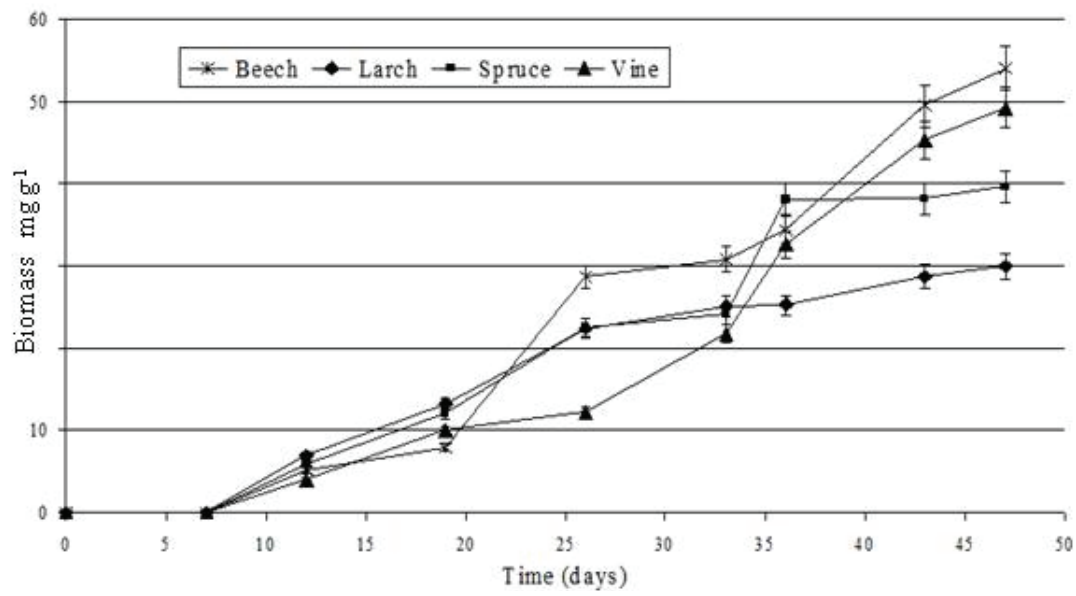

Fig. 6-Mycelium growth in glass jar fermenters. Results are expressed as mg of dry biomass per $g$ of solid-state fermented substrate. Main components of substrates are beech sawdust (\), larch sawdust (-), spruce sawdust (\$) and vine sawdust (一). tained on beech sawdust substrate.

The growth rate on larch sawdust-based substrate was $96 \%$ of the growth on beech substrate, while the amount of biomass was only $56 \%$ of the previous one. This was also visible when comparing the density of mycelia in racing tubes and glass jars. The mycelium was markedly less dense. Interestingly, the data for vine sawdust substrate was more favorable in terms of biomass accumulation, which achieved $90 \%$ of biomass accumulation on beech sawdust substrate, but showed lower growth rate (56\% of the growth rate of beech sawdust substrate). 

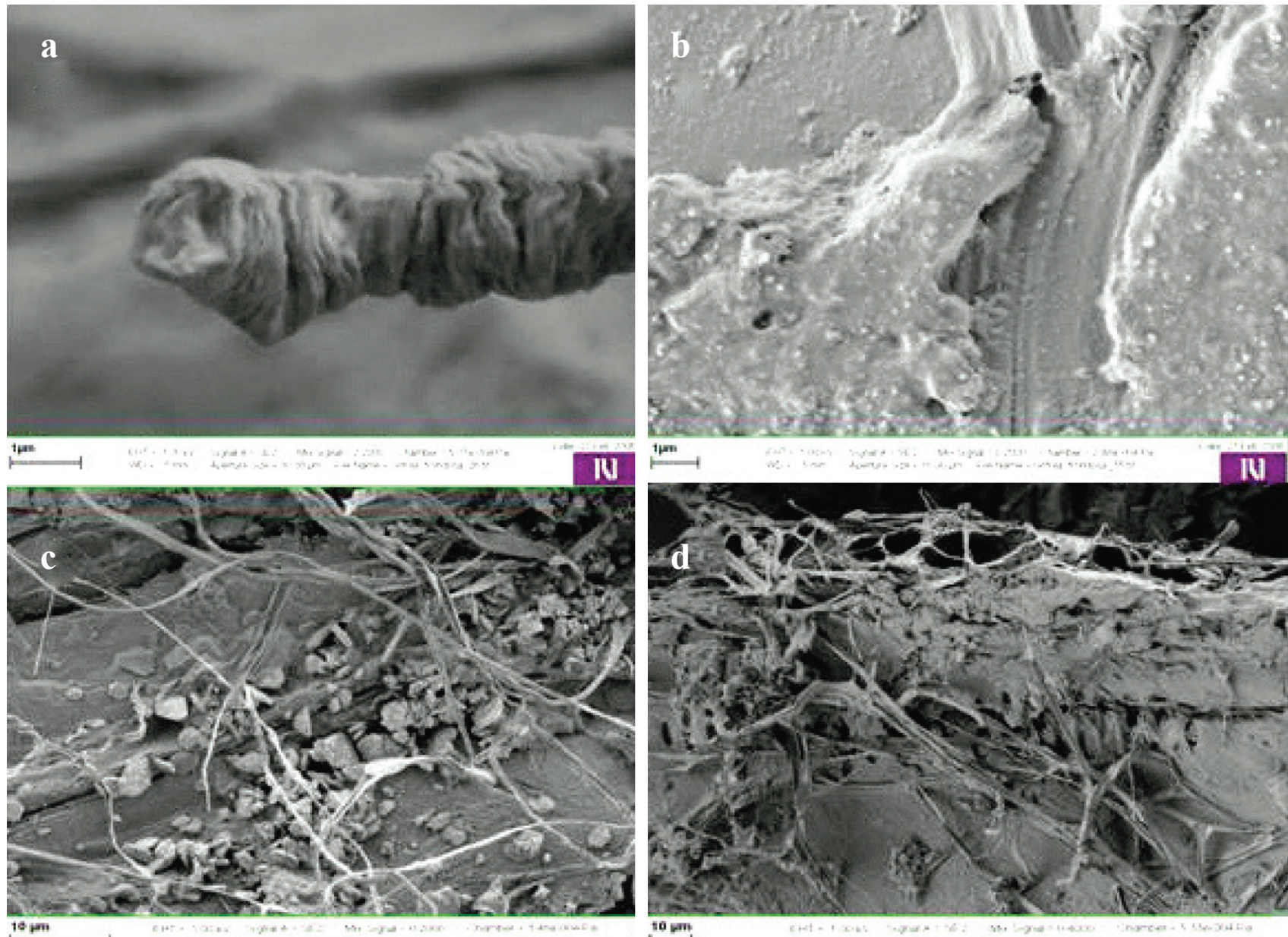

Fig. 7 - Mycelium from horizontal stirred tank bioreactor. (a) Fungal polysaccharide on the tip of young hyphae. (b) Sticky anchorages of hyphae tips on the cellulose matrix. (c) Mycelium growth on spruce sawdust (d) Vine sawdust-based substrate in the horizontal stirred bioreactor.

\section{Mycelium growth in the horizontal stirred tank bioreactor}

After the lag phase, mycelium grew concentrically on the surface of the solid particles and coaxially from the perforated shaft of impeller towards the walls of the bioreactor (Figure 3). During growth, the polysaccharides were secreted at the tips of young hyphae (Figure 7a). These molecules were used as sticky materials to produce the anchorage points for the movement of young hyphae, as well as transport medium for secretion of lignocellulolytic enzymes and a protective agent (Figure $7 b)$.

From our results, it was found that growth in the horizontal stirred tank reactor was closely parallel with the growth in the glass jar fermenter achieving the most comparable amount of biomass (53.2 $\mathrm{mg} \mathrm{g}^{-1}$ ) in only 42 days. The quicker growth rate can be attributed to aeration, as the glass jar fermenter only had passive ventilation. The total biomass produced in the solid-state fermenter after 42 days of incubation was $65 \mathrm{~g}$ dry weight.

\section{Conclusions}

Various substrates based on lignocellulosic sawdust particles from beech, Norwegian spruce, European larch and grapevine (sizes from 0.125 $\mathrm{mm}-0.5 \mathrm{~mm}$ ) were tested. The average ergosterol content in fungal biomass in measured samples was $5.80 \mathrm{mg} \mathrm{g}^{-1} \pm 0.04 \mathrm{mg} \mathrm{g}^{-1}$. The growth rates and biomass accumulation were different on each of the prepared solid substrates. As expected, the best results were obtained on beech sawdust substrate (3.76 $\mathrm{mm} \mathrm{d}^{-1}$ and $54 \mathrm{mg} \mathrm{g}^{-1}$ ). The remarkable differences were indicated on substrates composed of larch and vine sawdust substrates. The former was better in terms of growth rate and the latter in biomass production.

The results from the cultivation process in the horizontal stirred bioreactor, in terms of biomass per amount of solid substrate, compared at the same amount of biomass, indicated a faster cultivation process in aerated bioreactor. 
The growth area increased linearly (at $10.55 \pm$ $0.02 \mathrm{SD} \mathrm{mm} \mathrm{d}^{-1}$ ), while the biomass increased exponentially. Final dry biomass achieved at 21 days of incubation was $88.3 \pm 0.028 \mathrm{SD} \mathrm{mg}$.

\section{References}

1. Zhuang, C., Wasser, S. P., Medicinal Value of CulinaryMedicinal Maitake Mushroom Grifola frondosa (Dicks.:Fr.) S. F. Gray (Aphyllophoromycetideae), Int. J. Med. Mushrooms 6 (2004) 287. doi: http://dx.doi.org/10.1615/IntJMedMushr.v6.i4.10

2. Hsieh, C., Wang, H. L., Chen, C. C., Hsu, T. H., Tseng, M. $H$., Effect of plant oil and surfactant on the production of mycelial biomass and polysaccharides in submerged culture of Grifola frondosa, Biochem. Eng. J. 38 (2008) 198. doi: http://dx.doi.org/10.1016/j.bej.2007.07.001

3. Postemsky, P. D., Curvetto, N. R., Solid-state fermentation of cereal grains and sunflower seed hulls by Grifola gargal and Grifola sordulenta, Int. Biodeterior. Biodegradation 100 (2015) 52.

doi: http://dx.doi.org/10.1016/j.ibiod.2015.02.016

4. Huang, S. J., Tsai, S. Y., Lin, S. Y., Liang, C. H., Lian, P. Y., Mau, J. L., Preparation of culinary-medicinal Maitake mushroom, Grifola frondosa (Dicks.: Fr.) SF Gray (Aphyllophoromycetideae)-fermented wheat and its antioxidant properties, Int. J. Med. Mushrooms 13 (2011) 61. doi: http://dx.doi.org/10.1615/IntJMedMushr.v13.i1.80
5. Gregori, A., Pohleven, F., Cultivation of three medicinal mushroom species on olive oil press cakes containing substrates, Acta agriculturae Slovenica 103 (2014) 49. doi: http://dx.doi.org/10.14720/aas.2014.103.1.05

6. Gregori, A., Svagelj, M., Berovic, M., Liu, Y., Zhang, J. S., Pohleven, F., Klinar, D., Cultivation and bioactivity assessment of Grifola frondosa fruiting bodies on olive oil press cakes substrates, New Biotechnol. 26 (2009) 260. doi: http://dx.doi.org/10.1016/j.nbt.2009.08.001

7. Mau, J. L., Lin, H. C., Ma, J. T., Song, S. F., Non-volatile taste components of several speciality mushrooms, Food Chem. 73 (2001) 461. doi: http://dx.doi.org/10.1016/S0308-8146(00)00330-7

8. Stamets, P., Growing Gourmet and Medicinal Mushrooms. Ten Speed Press, Berkeley, USA (CA), 2000, pp. 366 374.

9. Mayell, M., Maitake extracts and their therapeutic potential - A review, Altern. Med. Rev. 6 (2001) 48.

10. Berovic, M., Ostroversnik, H., Production of Aspergillus niger pectolytic enzymes by solid state bioprocessing of apple pomace, J. Biotechnol. 53 (1997) 47. doi: http://dx.doi.org/10.1016/S0168-1656(96)01661-6

11. Gregori, A., Cordycepin production by Cordyceps militaris cultivation on spent brewery grains, Acta Biol. Slov. 57 (2014) 45.

12. Baath, E., Klamer, M., Estimation of conversion factors for fungal biomass determination in compost using ergosterol

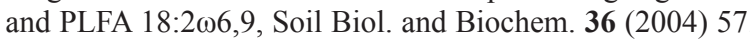
doi: http://dx.doi.org/10.1016/j.soilbio.2003.08.019 